\title{
LA COSECHA DE YERBA MATE (TAREFA): PARTICULARIDADES DE UN MERCADO DE TRABAJO Y SU CIRCULARIDAD LABORAL
}

\author{
The yerba mate harvest (tarefa): particularities of the labour market and its \\ labour circularity
}

\author{
Diana E. Haugg* \\ https://orcid.org/0000-0002-4335-1367
}

\section{Resumen}

En la Provincia de Misiones, la producción primaria de yerba mate estructura un importante mercado laboral, para el que se moviliza cada año un gran contingente de mano de obra rural (varones, mujeres y niños/ as), reconocidos regionalmente como tareferos (en plural y arbitrariamente masculino).

El objetivo del trabajo es analizar, a partir de fuentes primarias y secundarias, las particularidades del mercado cosechero/yerbatero, en la década de 1970, inquiriendo en las formas que asumían el empleo y las condiciones de vida de los/as tareferos/as. La investigación revela que, para su funcionamiento, dicho mercado se asienta en valores y costumbres instituidos regionalmente. Lo que conlleva una circularidad laboral donde no sólo circulan las personas, sino que la actividad misma circula entre las personas generacionalmente.

$<$ Mercado laboral $><$ Yerba Mate $><$ Tarefa $><$ Circularidad laboral $>$

\begin{abstract}
In the Province of Misiones, the primary production of yerba mate implies an important labour market, which annually requires the mobility of a large contingent of rural workers (men, women, and children), who are regionally recognized as tareferos (a plural noun which is arbitrarily categorised into masculine gender). The aim of this work is to analyze, from primary and secondary sources, the particularities of the harvesting/yerbatero market during the 1970s by inquiring into the employment and the living conditions of tareferos/as. The investigation reveals that the market of yerba mate is based on values and customs which are regionally established. This situation entails a labour circulation, which involves not only the circulation of people, but also the circulation of the activity from generation to generation.
\end{abstract}

$<$ Labour Market $><$ Yerba Mate $><$ Tarefa $><$ Labour Circularity $>$

Recibido: 02/03/2020

Aceptado: 18/07/2020

\footnotetext{
* Becaria Doctoral, Consejo Nacional de Investigaciones Científicas y Técnicas (CONICET). Universidad Nacional de Misiones, (UNAM), Argentina, hauggd@hotmail.com
} 
Haugg. La cosecha de yerba mate (tarefa): particularidades de un mercado de trabajo y su circularidad laboral.

\section{Introducción}

En Latinoamérica, en las últimas décadas, la vida laboral del mundo rural ha experimentado significativas transformaciones, que combinan nuevos escenarios con rasgos tradicionales del agro y la ruralidad. Esas mutaciones han abarcado tanto a las producciones agrarias como a los espacios o territorios rurales (Grammont de C, 2009), destacándose aquellas relacionadas a la movilidad o circulación de los/as trabajadores/ as y su inserción laboral. En Argentina, los procesos de reestructuración de las producciones agrarias, así como los de cambio social, han redefinido la configuración de las corrientes y patrones migratorios laborales transitorios, incorporando nuevos aportes al fenómeno (Quaranta y Blanco, 2012). La movilidad y circularidad laboral, para actividades agrícolas estacionales, constituye un componente histórico clave a la hora de la comprensión de la producción y reproducción social de unidades domésticas rurales o rururbanas.

Por ello, el objetivo de este artículo es analizar, desde una complementariedad interdisciplinaria, un mercado de trabajo particular en la Provincia de Misiones (Argentina), ${ }^{1}$ su circularidad laboral y la distancia social (real) de los/as agentes dentro del mismo. La propuesta es indagar las particularidades del mercado de trabajo yerbatero/cosechero en la década de 1970, inquiriendo en las formas que asumían el tipo y las condiciones de trabajo y de vida de los/as cosecheros/as de yerba mate, junto a la movilidad de la fuerza de trabajo en términos de espacios de corta distancia. De esta manera, el artículo revela que el mercado de trabajo yerbatero/cosechero - para su funcionamiento - se basa en valores y costumbres instituidos regionalmente, llevando de suyo una circularidad laboral, donde no sólo circulan las personas, sino que la actividad misma circula entre las personas.

Para esta empresa, se propone una revisión y análisis crítico de los resultados del "Estudio de la mano de obra transitoria en la Provincia de Misiones" (1972), llevado a cabo por el Grupo de Trabajo de Sociología Rural (en adelante GTSR), la construcción de datos a partir de una serie de entrevistas a cosecheros/as de yerba mate, y la ponderación de la bibliografía o literatura especializada. En particular, las valiosas contribuciones efectuadas por el sociólogo Víctor Rau quien, tal como lo plantea Gortari (2017), contribuyó a saldar una deuda histórica de las Ciencias Sociales en relación al análisis del mercado de trabajo yerbatero/cosechero.

Desde el punto de vista metodológico, la estrategia empleada es cualitativa y descriptiva, ya que es la que mejor se adecúa al trabajo que llevamos a cabo en este artículo. El principal insumo para la construcción de los datos sobre la década del '70 proviene del - ya mencionado- estudio del GTSR de la Dirección Nacional de Economía y Sociología Rural (1972). ${ }^{2}$ De diseño cuantitativo, éste produjo importantes

${ }^{1}$ Ubicada al nordeste del país, linda con la Provincia de Corrientes (Argentina), Brasil y Paraguay.

2 El estudio fue el resultado de un convenio entre la Dirección General de Estadística de la Provincia de Misiones y la Dirección Nacional de Economía y Sociología. El trabajo de campo fue llevado a cabo en los meses de julio y agosto de 1971, por el GTSR, a cargo de Carlos Flood y su equipo: Mercedes Caracciolo, Silvia Baudron, María Belén Dourron, Alicia Paura y Néstor Fuentes, teniendo como objetivo el análisis de la mano de obra transitoria en la cosecha de yerba mate y su inserción laboral, ya que el caso 
datos primarios a partir de la realización de entrevistas a 600 cosecheros de yerba mate y a 62 empleadores (diferenciados en 48 secaderos particulares, ${ }^{3} 6$ de cooperativas, 7 contratistas y 1 gran productor), ${ }^{4}$ seleccionando como muestra los departamentos Apóstoles, San Ignacio, Cainguás, Oberá, Eldorado y Montecarlo. ${ }^{5}$ Asimismo, el análisis propuesto se complementa con un trabajo de campo histórico-antropológico intermitente, prolongado y en curso. El mismo consta de relevamientos de archivos, hemerotecas, entrevistas y conversaciones informales, individuales, en dúo y grupales, con las que pudimos constatar una larga trayectoria de familias enteras dedicadas a la cosecha de yerba mate, de cómo la actividad circulaba por las unidades domésticas de donde partían los/as agentes, a las nuevas, conformadas con el tiempo, como una actividad "diaspórica" que acompañaba al agente.

Para este trabajo se utilizaron, de manera explícita o implícita, 10 entrevistas realizadas en las ciudades de Posadas y Oberá a cosecheros/as, residentes en esta última localidad. Por cuestiones metodológicas, de índole histórica y humana, nos encontramos imposibilitados para entrevistar a los mismos agentes que el GTSR, así que se han seleccionado entrevistas a cosecheros/as con una larga trayectoria como mano de obra para la cosecha de yerba mate. A la vez que presentan ciertas características comunes, como el cambio de residencia rural a periurbana o rururbana, tienen hijos y/o hijas, fueron empleados alguna vez por secaderos, han realizado y/o realizan pluriactividades y presentan una alta circularidad laboral interprovincial. Metodológicamente, interesa destacar el papel que juega la incorporación de las entrevistas, ya que dan "carne" y "cuerpo" a la muestra proyectada por el GTSR, enfatizando el punto de vista de los/as agentes en la revisión histórica efectiva del período y el estudio abordado, si bien no son los/as mismos/as. Hecho que supone, además, resaltar el punto de vista y los sentidos de los/as agentes aludidos como elementos ineludibles en el abordaje de la vida laboral del mundo rural yerbatero/cosechero.

El artículo está estructurado, a grandes rasgos, en una introducción de aspectos teóricos sobre los mercados de trabajo y la circulación laboral. Luego, se presenta el mercado yerbatero/cosechero explicando el proceso de cosecha de yerba mate y quiénes son los/as agentes encargados/as de dicha labor, seguido de dos apartados sobre la situación de trabajo, la circularidad y las condiciones de vida de los/as trabajadores/ as. Por último, un acápite donde expondremos la trayectoria de una cosechera, que resume la circularidad espacial e inter-generacional, además de dar a conocer, por un

\footnotetext{
yerbatero fue considerado como representativo en la Provincia de Misiones.

3 Los secaderos son las instalaciones en las que tiene lugar la primera etapa de industrialización o transformación primaria de la yerba mate. La misma consiste, básicamente, en tres procesos, dos de secado (el zapecado y el secado propiamente dicho) destinados a detener los procesos degradación de los tejidos del vegetal y alcanzar una deshidratación casi total, y uno de primera molienda (el canchado) que prepara el producto (la yerba canchada) para su posterior estacionamiento, molienda definitiva y empaquetado. Actualmente, existen tres tipos de secaderos de acuerdo al tipo de sistema de secado, a saber, barbacuá, a cintas, y rotativo.

${ }^{4}$ En total, para esos 62 empleadores trabajaban 1812 tareferos (GTSR, 1972).

5 La división territorial de la Provincia de Misiones comprende 17 departamentos, los que agrupan a 76 municipios.
} 
Haugg. La cosecha de yerba mate (tarefa): particularidades de un mercado de trabajo y su circularidad laboral.

lado, las distintas estrategias que ponían y ponen en marcha los/as integrantes de las unidades domésticas para reproducirse socialmente. Por el otro, hasta qué punto la misma actividad que realizan los/as agentes se convierte en la base en torno a la que se estructuran las estrategias.

\section{Mercado de trabajo y circularidad laboral}

Si partimos de que "lo económico ha sido definido inicialmente desde Platón hasta A. Smith como la riqueza material de las sociedades" (Godelier, 1967, p. 6), comprendemos mejor que la economía haya sido, generalmente, presentada y estudiada como una esfera autónoma. Gobernada por sus propias leyes, e independiente del resto de los procesos sociales y culturales. Explica, también, que la noción de "racionalidad" fuera situada en el centro del análisis de fenómenos económicos, o clasificados como económicos. Sin embargo, la noción de "economía" y, por ello, de lo "económico" ha sido deconstruida, por ejemplo, en la antropología económica, plasmando que los otros elementos del sistema social no son simples "datos exteriores" a tratar, sino que, más bien, los procesos económicos están íntimamente relacionados con diversas instituciones sociales y/o estructuras de parentesco. Por ello, la imposibilidad de describir lo económico sin mostrar, al mismo tiempo, su relación con otros elementos del sistema social.

En esa línea, el cientista austríaco Karl Polanyi (1976, p. 157) realizó una crítica epistemológica a los fundamentos del pensamiento económico clásico y neoclásico, a partir del "significado substantivo de lo económico", 6 procurando incrustar los actos económicos en la matriz cultural, política y social en la que se producen. Así, la economía humana estaría incrustada en instituciones económicas y no económicas (embeddedness). ${ }^{7}$ Por ende, sostiene Polanyi (1976, p. 159), "el sistema económico es, pues, un proceso institucionalizado". A partir de esto, el mencionado autor afirma que la actividad económica debe su existencia a una interacción de características culturales, las cuales dependen de estructuras institucionales definidas, cuya finalidad es el sustento de la sociedad en términos de "unidad" y "estabilidad" social. De esta manera, clasificará empíricamente las economías históricas como "formas de integración", distinguiendo como principales formas empíricas a la "reciprocidad", la "redistribución" y el "intercambio" (Polanyi, 1976, pp. 161-162).

Escapa a los alcances de este trabajo realizar un recorrido teórico sobre las "formas de integración", más bien han sido mencionadas, únicamente, para exponer que uno de los elementos fundamentales del análisis institucional de Polanyi, se centra en relacionar las estructuras institucionales que dan lugar a una forma de integración con las actividades y comportamientos de los agentes en una sociedad determinada. En definitiva, que los agentes no se comportan como individuos autónomos, motivados por

${ }_{6}$ Desde este punto de partida, para Polanyi, la economía vendría a ser el proceso por el que se obtienen medios de sustento para satisfacer las necesidades materiales.

7 La noción de embeddedness, fue introducida por Karl Polanyi para caracterizar la articulación entre la economía y otras esferas de la vida social en sociedades llamadas "primitivas". 
una “racionalidad económica".Al mismo tiempo que la organización de la vida económica no depende de interacciones de individuos aislados, en lucha por la maximización del sustento, ya que para su perspectiva institucionalista, son las instituciones culturales las que acuñan los comportamientos de los individuos. Por ello, teniendo en cuenta lo mencionado, nos enfocaremos en un mercado de trabajo agrario regional, dado que el mercado es el escenario privilegiado para el estudio de los distintos mecanismos que constituyen las formas que cobran las condiciones estructurales del mismo a través del tiempo. Además, porque es terreno de circulación de cosas y porque, como nos lo han enseñado la historia, la antropología y la sociología del mercado agrario en Argentina, los mercados son lugares de interconexiones entre grupos étnicos, zonas ecológicas, locus de "formalidades" e "informalidades", y demás (Bendini y Steimbreger, 2010; Gortari et al, 2017; Rau, 2005; Trpin y Rodríguez, 2015; entre otros).

El mercado de trabajo agrario yerbatero, al ser una institución social, presenta interesantes aspectos en torno a la circulación de personas. Polanyi (2007) define al mercado como institución social y, al hacerlo, nos incita a pensar a éste como resultado intencional de acciones políticas, económicas y culturales, más que una realización espontánea producto de actividades económicas. En tanto que, inspirado en Polanyi, Victor Rau (2006, p. 261), plantea que los mercados de trabajo agrarios se encuentran “inmersos en la sociedad, 'embebidos' por ella; a tal punto que el mercado de trabajo debe ser considerado como una institución social".

Respecto al mercado de trabajo yerbatero/cosechero -tomado como una institución social-, el estudio del GTSR manifestó la existencia de diversas formas de trabajo, de agentes específicos dedicados a la actividad, de prácticas económicas diversas, de segmentaciones internas en el mercado laboral. Al mismo tiempo, puso en evidencia que la discontinuidad y la estacionalidad de la cosecha de yerba mate -en la Provincia de Misiones- establece una demanda de mano de obra oscilante y cambiante, con fuertes períodos de inactividad, lo que obligaba a que los obreros rurales buscasen otro empleo. Esto demuestra la existencia de una segmentación por actividades económicas, tipos de ocupaciones y formas de remuneración. Asimismo, el informe confirma una alta movilidad de la mano de obra que no era regulada por el "libre juego de la oferta y demanda". Dicha movilidad será descrita, siguiendo a Chapman y Prothero (1984), como “circulación”, es decir como un movimiento de población repetitivo, de corto plazo o cíclico. ${ }^{8}$

Ante esto, es menester detenernos brevemente en lo que fue entendido, primeramente, como "migración de retorno", de manera de hacer más elocuente el tema a los fines del artículo. Los trabajos referidos a este concepto han comprendido análisis de corte histórico, antropológico, sociológico, demográfico, económico y político. Con enfoques cualitativo o cuantitativo, o encauzándose más en lo teórico o lo empírico. En 1980, George Gmelch publicó un ensayo denominado "Return Migration”, en el cual se elabora una tipología sobre los migrantes de retorno. En el mismo, observó las razones

8 La característica más común de este tipo de movilidad es que los agentes no planean ni intentan reubicarse permanentemente. 
Haugg. La cosecha de yerba mate (tarefa): particularidades de un mercado de trabajo y su circularidad laboral.

para volver, la adaptación y el reajuste de los retornados, como así también el impacto de la migración de retorno en las sociedades de origen. Gmelch llegó a la conclusión de que todos los estudios sobre retorno, hasta el momento, eran descriptivos y aludían a las poblaciones de retorno específicas como una unidad especial, con experiencias únicas, dejando de lado las similitudes entre los agentes.

En 1984, se publicó "Themes on Circulation in the Third Worl", trabajo en el que Chapman M. y Prothero M. -superando los estudios descriptivos y centrándose en una temática poco atendida en la academia-abordaron el análisis de la "circulación" o "flujo recíproco de personas" en -definidas por ellos- sociedades del "Tercer Mundo". Estos autores sostienen que la "circulación" o "flujo recíproco de personas" ha sido desatendida por los estudiosos en ciencias sociales, más concentrados en los desplazamientos denominados "migración", hasta los años ochenta. Además, los mismos afirman que, para comprender en profundidad la compleja naturaleza de las personas que circulan, dicha circulación debe ser analizada en varias escalas: "the micro (individual, family), the meso (community, settlement system, region) and the macro (country, continent, world). Consequently the measurements and techniques to be employed are of critical importance and the data must be both longitudinal and cross-sectional" (Chapman y Prothero, 1984, p. 622). A su vez, destacan la necesidad de enfocarse en las estructuras sociales, políticas y económicas, las cuales vinculan e inciden recíprocamente en los flujos recíprocos.

En definitiva, enfocándonos en lo que nos concierne en este trabajo, destacamos que Chapman y Prothero (1984) se han configurado -en el tiempo-como autores clásicos, que tratan el estudio de la circulación de personas en sociedades calificadas como "Tercer Mundo". En esa dirección, desde el punto de vista terminológico, los autores han sido prolíficos en la concepción y proposición de diversas expresiones o vocablos como "migración de retorno", "movilidad circular", "circulación", "circularidad", "circularidad migratoria", "circulación laboral", entre otros. No obstante, ante aquella anarquía conceptual, han establecido una distinción básica entre "migración" y "circulación", fijando el regreso al lugar de origen como criterio de diferenciación entre "migración" (permanencia en el lugar de destino) y "circulación" (intercambio de individuos y/o pequeños grupos de personas entre lugares -orígenes y destinos-, que concluye en el lugar que comenzó); ${ }^{9}$. A su vez, llamaron la atención sobre conceptos híbridos como "migración circular", los cuales únicamente podrían ser ocupados en condiciones excepcionales.

Varios son los autores que continuaron el trabajo de Chapman y Prothero (1984), analizando y documentando las distintas dimensiones que atraviesan los desplazamientos de grupos humanos. Algunos de ellos señalan la aceleración de los movimientos de población, su gran heterogeneidad y complejidad, así como la diversidad de los agentes

9 En palabras de los autores, "standard work on movement in third world societies has emphasized migration, which involves a shift in permanent residence from one domicile to another, but fails to consider the constant interchange of people between diverse places and different circumstances. Many moves, as from villages and towns, are in fact circulatory: they begin at, go away from, but ultimately end in the same dwelling place and community" (Chapman y Prothero, 1985, p. 19). 
que involucran estos movimientos. Cobran visibilidad especialmente la feminización y la etnización de los migrantes y circulantes, y la movilidad o circularidad cíclica o laboral, en detrimento de la migración "clásica" y unidireccional (Bendini y Steimbreger, 2010; Lara Flores, 2010; Tarrius, 2000; Trpin y Rodríguez, 2015). Específicamente, aquí la "circularidad laboral" recobra vital importancia, ya que nos sirve para discurrir los posibles indicadores de las formas de trabajo, de segmentaciones (como los montos salariales diferentes por departamentos) las formas materiales de pago, la circulación interdepartamental de familias enteras y no sólo de trabajadores directos, las diferencias de sexo/género y etarias al interior del grupo, la circularidad laboral intra-familiar por generaciones. Todo lo cual demuestra que el mercado de trabajo yerbatero/cosechero fue institucionalizado, y no existe al margen de las disposiciones adquiridas de los agentes que lo dinamizan. De esta manera, lo económico es enfatizado como hecho social, sobre todo por la circunstancia de que los y las agentes que "circulan" para la cosecha de yerba mate incorporan distintas dimensiones, no sólo económicas, sino también, culturales, sociales y políticas.

\section{Mercado de trabajo cosechero/yerbatero}

Una parte importante de la literatura especializada en la temática sostiene que Argentina es un país que presenta un elevado desarrollo del capitalismo, en su sector agrícola, con diferencias y variaciones en las regiones productivas o regiones sociales. Dentro de cada una de estas regiones, existen una multitud de agentes sociales involucrados en distintos procesos de crisis, intentos de supervivencia, expansión (Aparicio y Benencia, 1999), circulación, migración o expulsión. Una de esas regiones productivas es la que concentra el $90 \%$ de la producción nacional de yerba mate y, a su vez, dinamiza un extenso mercado de trabajo agrario -asalariado y familiar, permanente y transitorio- donde no se discriminan para el uso de fuerza de trabajo, ni sexos, ni edades. ${ }^{10}$ Esta región está integrada casi en su totalidad por la provincia de Misiones, que se ha caracterizado por poseer una estructura agraria/yerbatera particular, la cual fue sufriendo transformaciones a lo largo del tiempo.

Asimismo, en Argentina, en la década de 1970, la presencia de fuertes migraciones rural-urbanas constituía el correlato inevitable de la disminución de los niveles de ocupación agrícola. No obstante, en Misiones el problema fundamental no radicaba en el hecho de la emigración del campo a la ciudad, sino más bien en el insuficiente crecimiento de la ocupación industrial, que no lograba absorber los excedentes de la mano de obra rural. Para el caso de la producción de yerba mate, era $-\mathrm{y}$ sigue siendo- su existencia como estructura productiva que no permitía formas adecuadas de ocupación a gran parte de su mano de obra, no garantizando, para las mismas, un grado mínimo de estabilidad ocupacional. Sumada a esta falta de

${ }^{10}$ La yerba mate (ilex paraguarienses) es un árbol nativo de la selva paranaense, en estado silvestre puede alcanzar hasta 16 metros. En su estado elaborado es absorbido mayoritariamente por el mercado interno, en base al consumo de mayo del 2019 , se calcula que se consumen $6,8 \mathrm{~kg}$ anuales por habitante en Argentina (INYM, 2019). 
Haugg. La cosecha de yerba mate (tarefa): particularidades de un mercado de trabajo y su circularidad laboral.

estabilidad, existían períodos de mayor demanda de mano de obra, en los cuales el gran volumen de obreros/as requeridos hacía necesario el aporte de obreros rurales extranjeros, tales como paraguayos, bolivianos y brasileños. ${ }^{11}$ Por lo que, en la provincia en épocas de cosecha de yerba mate, circulaban obreros rurales de países limítrofes, como así también los "locales", trasladándose a distintos puntos de la provincia, pero siempre cercanos a su domicilio de origen, como se verá más adelante.

Por esos años (hoy en día también), el período de cosecha de yerba mate abarcaba los meses que van de abril a septiembre, cuando se realizaba el grueso de la cosecha y, en menor proporción en los meses de diciembre, enero y febrero. Este último período es conocido regionalmente como zafriña de verano. ${ }^{12}$ La tarea rutinaria empezaba cuando pasaba el contratista con un camión, a buscar a los obreros/as por su domicilio, entre las 4 y 5 de la mañana. ${ }^{13} \mathrm{~A}$ su vez, si la cosecha tenía lugar en un yerbal alejado, los asalariados acampaban por 15 días a la intemperie o bajo carpas improvisadas de polietileno. Una vez instalados, comenzaban a cosechar ni bien había suficiente luz (lo que se modifica de acuerdo con la estación del año). El tiempo trabajado por día variaba entre 10,12 y hasta 14 horas. ${ }^{14}$

Durante la cosecha se realizaba una operación denominada viruteo, que consistía en extraer manualmente, de adentro hacia afuera y de abajo hacia arriba, solo las ramas finas, tratando de dejar un brote en cada rama de la planta para aumentar su productividad (15 a 20\% de la cosecha). Otra parte del proceso se conocía como corte y quiebre, en la que el/la obrero/a cortaba cuidadosamente las ramas cargadas con hojas empleando la mano, una tijera o un serrucho (de acuerdo con su capacidad de adquisición de las herramientas y el grosor de las ramas) y se quebraban las hojas, separando las más gruesas de las hojas sueltas ( 80 a $85 \%$ de la cosecha). Al finalizar la cosecha de la planta, se proseguía a recolectar y acumular la yerba de manera apilada en unas bolsas de arpillera, denominadas ponchadas, para su posterior pesaje, que al unirse sus cuatro extremos forman un raído con toda la hoja verde acumulada -de 100 kilos aproximadamente-. Esos raídos eran pesados y cargados en un camión de carga, que obraba de medio de transporte

\footnotetext{
${ }^{11}$ GTSR, 1972. En este caso, el número de agentes transfronterizos era mínimo (7\% de la mano de obra), según lo presentado por la investigación en cuestión. Unas décadas más tarde era nulo, ya que, a partir de la década de 1990 hubo un sobreofertado de mano de obra para la cosecha, no pudiendo ser absorbida en su totalidad por el mercado. Por lo que no se hace necesario, para este mercado en particular, apelar a herramientas conceptuales para comprender la dinámica de sujetos transmigrantes (Trpin y Rodríguez, 2015) que traspasan fronteras como parte de sus trayectorias laborales, configurando territorios migratorios como sustento del desarrollo de nuevas identidades (Tarrius, 2000).

${ }^{12}$ En todo el texto, las itálicas señalan el uso nativo de la expresión.

${ }^{13}$ Actualmente, el desempeño de la actividad poco ha cambiado respecto a aquellos años. El principal cambio reviste en que ahora se está expandiendo la implementación de la cosecha semi-mecanizada. Esto consiste en una tijera eléctrica, una cortadora de ramas y un artefacto similar a una cadena que suple los nudos de los raídos, haciendo un poco más liviana la actividad, pero los pasos son los mismos de antaño.

${ }^{14} \mathrm{Los} /$ as obreros/as rurales en la cosecha se exponían a condiciones climáticas inestables (intensas lluvias, heladas, altas temperaturas solares), además, como es una actividad al aire libre, era habitual que los cosecheros/as se rompan y mojen la ropa con el rocío de la planta (la misma debía ser secada en su propio cuerpo en el transcurso del trabajo), se lastimasen las manos y se cortasen el cuerpo.
} 
de la materia prima hacia los secaderos y cooperativas y, de medio de transporte de los/las trabajadores/as hacia sus domicilios o el lugar de acampe.

Todo lo anterior sirve de antesala para lograr lo que buscamos: profundizar el análisis del mercado de trabajo agrario, estructurado en torno a la cosecha de yerba mate. Más específicamente, nos centramos en el estudio del GTSR que, además de presentar las variaciones en el monto salarial de acuerdo a los departamentos provinciales, las pluriactividades en épocas de interzafra, etc; logra dar cuenta, con sustento empírico, de las diferencias al interior del mercado de trabajo. Además, permite explicar la situación laboral, la determinación de los "ingresos", "migración de tipo rural-rural", la segmentación entre trabajadores fijos y temporales, entre los locales y los "migrantes" (paraguayos, bolivianos y brasileños), y entre las mujeres y los varones. ${ }^{15}$ Lejos de los fines del trabajo está la realización de un derrotero histórico sobre la constitución social del mercado de trabajo yerbatero, ni de los mecanismos laborales presentes en los mismos desde sus orígenes, ni la figura del mensú y su origen étnico. ${ }^{16}$ Más bien, nos centraremos en la figura encarnada por el tarefero ${ }^{17}$-presentado como prominentemente masculino, pero también es femenino-expuesta en el "Estudio de la mano de obra transitoria de la Provincia de Misiones". Se debe a que éste, de manera implícita, impone un cuestionamiento al homo economicus, de modo que, en su análisis se desprenden las capacidades y propensiones prácticas de los agentes que cosechan yerba mate para interpretar, improvisar y resolver situaciones a corto y largo plazo, y no necesariamente con consciencia de los mismos.

Para la década de 1970, la producción agrícola de yerba mate absorbía una gran cantidad de mano de obra en la Provincia de Misiones. Tal es así, que para el año 1971 -según datos proporcionados por la Comisión Reguladora de la Yerba Mate (CRYM) - se estimó en 235.692.252 kg. la yerba canchada cosechada, donde el trabajador transitorio -arbitrariamente en masculino- era cuantitativamente más importante, 9940 personas. ${ }^{18}$ Sin embargo, el GTSR sostenía que se trataba de una cifra muy baja, porque no se tenía en cuenta a los cosecheros que ingresaban al mercado por fuera de

\footnotetext{
${ }^{15} \mathrm{Si}$ bien, el estudio no hace referencia explícita sobre diferenciación social entre mujeres y varones, al describir la remuneración o el tipo de trabajo se dejan entrever las diferencias entre unos/as y otros/as; las que no son más que parte de un proceso interno del mercado de trabajo agrario de yerba mate localizado en la génesis del mismo.

${ }^{16}$ El mensú es el agente histórico encargado de explotar los yerbales de la selva nativa en el período que se extiende, aproximadamente, desde 1875 hasta la década de 1930. Se cree que su denominación de "mensú" hace "alusión al pago de una mensualidad, el vocablo apunta ya hacia la forma de relación salarial moderna" (Rau, 2005, p. 37), por ello mensú devendría del término "mensualero". Su origen étnico es el aborigen guaraní y el mestizaje español (Rau, 2006).

${ }^{17}$ El tarefero es el descendiente histórico del mensú. Siendo, el vocablo regional con el cual se identifica a los/as cosecheros/as de yerba mate a partir de las décadas de 1930-1940.

${ }^{18}$ Dicha cifra fue estimada -siguiendo una lógica estadística- por los autores del informe del GTSR, ya que hasta la fecha no existe un registro con el que podamos establecer la cantidad de mano de obra registrada para la cosecha, debido a las "irregularidades" en la contratación. El Censo Agropecuario de 1969 arrojó la cifra de 88.948 personas ocupadas en explotaciones agropecuarias en la provincia, no obstante, no existe un registro que permita desagregar ese dato para llegar a la población en estudio, es decir la mano de obra transitoria ocupada para la cosecha de yerba mate.
} 
Haugg. La cosecha de yerba mate (tarefa): particularidades de un mercado de trabajo y su circularidad laboral.

las fechas "oficialmente" pautadas y, en ocasiones, la movilidad ocupacional, es decir, la circulación de cosecheros por distintos departamentos de la provincia. Igualmente, ese número, proporcionado por la (CRYM) a los investigadores del GTSR, no consideraba a la tarefa como un trabajo familiar. Por ello, otra circunstancia importante es conocer que los tareferos no trabajan los 365 días del año cosechando, porque la cosecha tiene sus meses de trabajo prefijados con anterioridad a la misma. Como se ha mencionado antes, el auge de la cosecha es entre los meses de abril a septiembre, en menor medida, se extiende a los meses de diciembre-enero-febrero (zafriña de verano). Entonces, en el mejor de los casos, si todos los asalariados agrícolas llegaron a trabajar 9 meses al año y en un promedio de 7.4 días por quincena en el yerbal, esto daría un total de 135 días laborales anuales. Pero si sólo trabajaron 6 meses con 15 días laborales en el yerbal, los días de trabajo serían, solamente, 90 anuales. ${ }^{19}$

\section{Situación de trabajo, circulación de la mano de obra y actividad generizada}

Hacia 1970, el cosechero transitorio de yerba mate era contratado por un secadero particular, una cooperativa, un productor o por medio de un intermediario: el contratista. El contratista podía ser contratado, a su vez, por los secaderos o productores. Por ejemplo, en San Ignacio, Cainguás y Oberá, los secaderos no contrataban directamente la mano de obra, sino que trabajaban con contratistas. Estos eran quienes se encargaban del reclutamiento, control y pago de los cosecheros, pero trabajando para un solo secadero. Este último sólo proporcionaba el dinero para pagar los salarios o, en otros casos, el contratista recibía una remuneración proporcional a la producción que cosechaba su cuadrilla ${ }^{20}$. Cabe aclarar que el contratista no era un agente elegido al azar, éste debía contar con cierto capital económico, en la mayoría de los casos era un camión para transportar a los cosecheros/as a las plantaciones y la respectiva yerba al secadero. Además, ostentaba capital social -en términos de Bourdieu (2015)-, logrando entretejer vínculos sociales con los cosecheros de yerba mate, los cuales veían en éste la figura del "patrón", consiguiendo, así, desligar todo vínculo directo entre las partes, especialmente cuando se trataba de "movilidad territorial" o "ecológica" de la mano de obra $^{21}$. Así, el contratista a través de redes sociales establecía contactos con empleadores de algún departamento que no era el de la residencia de los trabajadores, reclutando y trasladándolos a cosechar a ese departamento, pero "devolviéndolos" a sus respectivos departamentos una vez finalizada la cosecha.

Ese momento, en el que se producía el desplazamiento de los trabajadores como "movilidad ecológica", es descrito también como "migración rural-rural" por el GTSR, refiriéndose a los desplazamientos geográficos que realizaba la mano de obra relacionada

\footnotetext{
${ }^{19}$ El promedio de 7.4 días laborales por quincena fue tomado del trabajo del GTSR (1972) y en base a entrevistas a tareferos/as. El número de 15 días de trabajo por mes se debe a las inclemencias temporales, principalmente la lluvia de invierno, ya que Misiones tiene un clima subtropical sin estación seca, lo que hace que lluevan muchos milímetros al año. Una vez que llueve no se puede cosechar.

${ }^{20}$ GTSR, 1972.

${ }^{21}$ GTSR, 1972, p. 51.
} 
a su movilidad ocupacional. ${ }^{22}$ Además, sostenían que debido a la ocupación precaria que revestían las actividades agrícolas en la provincia, mayor era la "migración" del trabajador rural. En materia de ello, optamos por denominar a ese fenómeno "circularidad laboral" -en este caso interdepartamental-, siguiendo a Chapman y Prothero (1984), ya que esta circulación de trabajadores no alteró la distribución a largo plazo de dichos agentes; lo que, a su vez, es un ejemplo más de que un mercado, sea cual fuere, no es una unidad aislada porque, si bien opera en un espacio específico, supone contactos, intercambios, etcétera.

Respecto a los números que arrojó el estudio en cuestión, corresponde señalar que el mismo no analizó la circularidad laboral dentro de un mismo departamento, ya que por razones metodológicas consideraron que existía movilidad ecológica cuando los cosecheros cambiaban de departamento ${ }^{23}$. Sin embargo, dentro de un mismo departamento existen varios municipios rurales, lo que implicaba trasladarse y habitar - en las históricas carpas de polietileno- en el municipio donde se cosechaba, incluso por varios meses, por lo que no hacía la diferencia que la distancia fuere de 20 o 100 kilómetros ${ }^{24}$.

"Un 28\% de los encuestados se han trasladado a trabajar durante el año a zonas distintas del departamento donde se los registró por medio de la encuesta. La movilidad interdepartamental se registró en un 14\% de los cosecheros, predominando el traslado a departamentos adyacentes. Es asimismo destacable la proporción de aquéllos que cambian de provincia. En este grupo figuran 44 sujetos, de los cuales 21 son correntinos que se trasladan a Misiones para la tarefa, 2 vienen de otras provincias y de los 21 casos restantes son misioneros que residen en Misiones pero en algún momento del año han ido a trabajar a otras provincias (...) Cuando ésta [la cosecha] finaliza esos contingentes retornan a sus lugares de residencia" ${ }^{25}$.

El resto, el 71\%, destacó cosechar siempre en el mismo departamento, pero no en el mismo lugar. De acuerdo con esto, se puede señalar que la circularidad laboral

\footnotetext{
${ }^{22}$ La movilidad ocupacional refiere a la rama de actividad y el grado de estabilidad de todas las tareas que haya desempeñado el cosechero en el año 1971, aparte de la tarea de cosechar yerba mate -principal actividad-. La mayor parte de los entrevistados, se caracterizaban por una movilidad ocupacional con preeminencia de tareas rurales inestables durante todo el ciclo anual. El $68 \%$ de los cosecheros alternó durante el año tareas rurales inestables, el $13 \%$ en tareas rurales semi-inestables, el $9 \%$ trabajó en el sector servicios, el $6 \%$ en el sector industrial y el $1 \%$ en la actividad comercial relacionada a la venta ambulante. Ninguna tarea implicó estabilidad, puesto que sólo eran trabajos temporales (GTSR, 1972).

${ }^{23}$ GTSR, 1972.

${ }^{24}$ En reiteradas entrevistas realizadas, los/as tareferos/as afirmaron no volver a sus domicilios diariamente cuando salen de su municipio. Es decir, que se puede estar en el mismo departamento pero en un municipio adyacente, lo que implica una mudanza temporal con toda la unidad doméstica, que puede variar de 15 días a meses.

${ }^{25}$ GTSR, 1972, pp. 51-52.
} 
Haugg. La cosecha de yerba mate (tarefa): particularidades de un mercado de trabajo y su circularidad laboral.

estaba determinada por la intervención de los contratistas - señalados anteriormente- y de aspectos culturales que "hacen" al mercado de trabajo cosechero/yerbatero. Por lo tanto, no sustentada en "las fuerzas económicas" y regulada por el "libre juego de oferta y demanda", para la cual los/las trabajadores/as serían atraídos/as individualmente. Ya que, según el análisis cualitativo del documento, la circularidad de la mano de obra respondía a la "necesidad de conservar un mínimo nivel de subsistencia"26.

Por lo tanto, tal como lo plantea Lara Flores (2001, p. 366) para mercados agrícolas de este tipo en México, el mercado de trabajo cosechero de yerba mate bajo esta configuración, “...no es un lugar donde oferentes y demandantes se encuentren libremente, porque tanto la oferta como la demanda se encuentran mediada por contextos sociales y culturales complejos que segmentan a los trabajadores en un sinnúmero de categorías". Éstas pueden incluir las de clase, etnia, sexo y generaciones. Esto se debe a que el mundo de trabajo rural cosechero ha enfrentado, históricamente, un abanico muy amplio de situaciones complejas en su exterior como clase histórica en desventaja en general, y en su interior bajo criterios creados en torno a su sexo, su edad y, en algunos casos, su etnia. De la misma forma, la dimensión más importante de la "situación de trabajo", el ingreso, también está mediado por el contexto social y cultural y por las segmentaciones internas: "mediante el análisis del ingreso se puede conocer el grado de deterioro económico en que se encuentra el tarefero en Misiones, no sólo en tanto tarefero, sino en cuanto a mano de obra rural en Argentina"27.

Las remuneraciones al asalariado agrícola no tienen nada de diáfanas, en el sentido de una forma de "salario periódico", debido a que el salario no se establecía en base a acuerdos contractuales entre obreros sindicalizados y representaciones empresariales. Incluso, si se trataban de tareferos con un contrato formal por medio de los secaderos, las paritarias de 1971 debían haberse expedido en enero, ${ }^{28}$ no obstante -por razones indeterminadas-, la resolución que debiera establecer un aumento salarial para enero fue promulgada recién para el 30 de septiembre, cuando estaba terminando la cosecha de ese año ${ }^{29}$.

Además, en la estimación del salario influían diferentes características que no estaban reguladas, relacionadas a:

a) La "participación" del grupo doméstico en la obtención del ingreso del contratado;

b) Las variaciones en el monto de ingreso de acuerdo a los departamentos provinciales en los que se trabajase; ${ }^{30}$

\footnotetext{
${ }^{26}$ GTSR, 1972, p. 54.

${ }^{27}$ GTSR, 1972, p. 8.

${ }^{28}$ Regía la Ley 13.020 de protección al trabajo de cosecha y las denominadas Comisiones Paritarias Locales promulgadas en 1949, reglamentadas por el Estatuto del Peón.

${ }^{29}$ GTSR, 1972.

${ }^{30}$ En términos de "mejor paga", de acuerdo a los departamentos encuestados, tenían el siguiente ordenamiento: Montecarlo, Eldorado, Oberá, San Ignacio, Cainguás y Apostóles (GTSR, 1972, p.12).
} 
c) La forma material en que el trabajo era retribuido (dinero, alimentos, vales $^{31}$ etc.), y cómo variaba según el empleador;

d) La forma y el lugar en los que los/as tareferos/as compraban sus provisiones (en efectivo en un almacén del lugar de residencia, en efectivo en la cantina del contratista o del secadero, por medio de libreta de deuda en la cantina del contratista, a través de un adelanto en alimentos antes de comenzar la cosecha, etc.) y cómo variaba según el tipo de empleador;

e) El sobreprecio que debía pagar por la provista ${ }^{32}$ y cómo variaba dicho sobreprecio según el tipo de empleador y el lugar donde trabajase el obrero.

Ante este panorama, lo primero es señalar que el tarefero habitualmente no trabajaba sólo, principalmente en la tarea de corte y quiebre, porque varios integrantes de la unidad doméstica intervenían en calidad de "ayuda o colaboración" ${ }^{33}$. Por eso, se establece que un tarefero sólo podría cosechar en promedio 300 kilos de yerba por día de acuerdo: a las particularidades del yerbal, a si es un yerbal viejo o un yerbal nuevo, y a la edad, salud corporal y habilidad práctica del obrero. Las demás personas que "ayudaban" a cosechar incrementaban la producción del obrero que fue contratado, y esto hace que, de acuerdo al número de personas que intervenían en la tarefa, se pueda obtener el promedio de kilos cosechados por día. Se consideraba a la tarea que realizaba el tarefero en el yerbal (un adulto de sexo masculino) como "trabajo directo", y a la tarea que realizaba el resto de la familia o unidad doméstica se la denominaba "ayuda": "una gran cantidad de personas que intervienen en la tarefa en calidad de 'ayuda' o 'colaboración' del cosechero. Esta ayuda generalmente corresponde a los integrantes de su familia (mujer, hijos, padres y otros parientes)" "34. Es decir, que el tarefero que tenía el vínculo con el empleador percibía el ingreso por todo el grupo familiar.

El eufemismo "ayuda familiar", usado para describir el trabajo de mujeres y niños/as, llama la atención acerca del lugar particularmente desventajoso de éstos en el mercado laboral, cuyo trabajo no era valorado como "asalariado". Por ello, hay que subrayar que, en el mercado capitalista yerbatero, el sexo biológico devino la única razón de las diferencias entre varones y mujeres. ${ }^{35}$ Se subrayó, con tanto énfasis, las diferencias funcionales y biológicas entre los sexos que se terminó por legitimar e

\footnotetext{
${ }^{31}$ Los vales -aun en vigencia- son papeles, en la mayoría de los casos, escritos a mano, cuyo carácter reviste el de una especie de "moneda social". No obstante, esa "moneda social" era únicamente válida -en este caso- entre los/las tareferos/as y el comercio seleccionado. Los/as asalariados/as agrícolas recibían ese vale como forma de pago para comprar en un local comercial donde el contratista realizó con anterioridad las transacciones necesarias, encontrándose obligados a comprar en ese comercio al precio que fuere. Curiosamente, la mayor de las veces los dueños de los comercios eran contratistas o encargados de los secaderos.

${ }^{32}$ Regionalmente se denomina provista a una serie de alimentos básicos no perecederos para consumo familiar. Es una categoría nativa tomada por los investigadores.

${ }^{33}$ GTSR, 1972.

${ }^{34}$ GTSR, 1972, p. 30.

${ }^{35} \mathrm{Si}$ bien los/as niños/as también fueron considerados dentro de la categoría de "ayuda familiar", si eran varones en algún momento pasaban a ser trabajadores directos, no así si fueren niñas. Para un análisis más profundo del trabajo infantil en la cosecha de yerba mate, véase Re (2015).
} 
Haugg. La cosecha de yerba mate (tarefa): particularidades de un mercado de trabajo y su circularidad laboral.

institucionalizar estas diferencias como base de la organización social cambiante en el tiempo y el contexto histórico, pero residual en la experiencia laboral femenina. Se describen a los empleos como si éstos poseyeran, en sí mismos, ciertas cualidades propias de uno u otro sexo con una edad específica, siendo el trabajo en el yerbal considerado masculino.

En los yerbales, el trabajo de las mujeres y de los/as niños/as se confunde con el trabajo en general, su historia, su vivencia, su existencia misma se localiza en los suburbios de lo considerado una peripecia, de lo designado un trabajo de "varones" (adultos). En este punto, es menester remarcar que, la "reproducción biológica y social", es decir la forma de reproducción de los agentes como factor fundamental de la reproducción de las relaciones de producción (Melliasoux, 1977), implicó una gran ventaja al capital. Éste se apropió -y apropia- cuasi gratuitamente de una inmensa cantidad de trabajo (no reconocido) realizado por las mujeres tareferas, en nombre de la "naturaleza", del "amor" o del deber maternal y matrimonial ${ }^{36}$. En consecuencia, es ineludible devolver a la acción histórica la relación entre los sexos, lo que la visión naturalista les niega. Esta visión ha representado algo así como el estancamiento de la rueda de la historia, al excluir de forma arbitraria a uno de los sexos como parte de la "socialización de lo biológico y la biologización de lo social" (Bourdieu, 2000, p.160). Sin duda, la razón de esto es de índole cultural y social. Poco tiene que ver con costos y productividad, ya que en el caso de las mujeres, estas lograban cosechar los mismos kilos de yerba que sus pares masculinos. Cabe aclarar que el estudio del GTSR movilizaba preguntas e hipótesis, propias del enfoque de la sociología rural Argentina de la época, por lo que concibió al trabajo femenino como "ayuda familiar", tal vez apelando a categorías nativas que circulaban entre los agentes encargados de cosechar yerba mate. ${ }^{37}$

Retomando, hay que señalar, además, otra característica relativa al ingreso, a saber, que "el pago por el trabajo realizado se efectúa a destajo, es decir 'por cantidades' del producto cosechadas por cada individuo o equipo" (Rau, 2005, p. 101). Efectuándose quincenalmente, en el momento en que el obrero recibe su salario nominal. Según el artículo 23, de la Resolución C. N. No 88/71, se fijó para la cosecha de 1971 el pago de $0,38 \$$ ley los $10 \mathrm{~kg}$. de yerba mate cosechada en yerbales nuevos. ${ }^{38}$ Sin embargo,

\footnotetext{
${ }^{36}$ Las cosecheras de yerba mate tienden a denominarse a sí mismas mujeres tareferas y no tareferas a secas. Por eso se ha optado por utilizar la categoría nativa de identificación o autodenominación.

${ }^{37}$ Hugo Amable (2012, p. 35) estudió el campo léxico en Misiones en la década de 1970, estableciendo que, el agente encargado de la cosecha era un varón, el tarefero. Y, que ese sustantivo no tenía femenino a pesar de verse mujeres dedicadas a esa labor. "Claro que no se tratan de mujeres solas, sino de mujeres que ayudan al marido; es decir que no es una tarea de esas que la mujer realiza independientemente". Lo cual negaba y desvalorizaba el trabajo femenino en los yerbales.

Sumado a ello, existieron transformaciones en las relaciones sociolaborales en el mercado de trabajo yerbatero, en la década de 1990, que fueron abordadas pormenorizadamente por Víctor Rau (2005) y, complementando dichas investigaciones, hemos analizado en un trabajo anterior (Haugg, 2018) cómo, recién a partir de los noventa, comenzó a materializarse la asalarización de las mujeres cosecheras en el contexto de un mercado sobreofertado de mano de obra.

${ }^{38}$ En el estudio del GTSR los precios están calculados en peso moneda nacional ( $\left.\mathrm{m} \$ \mathrm{n}\right)$, moneda vigente en Argentina hasta el año 1969.
} 
la mayoría de los encuestados recibió la cantidad de $0,25 \$$ ley por los $10 \mathrm{~kg}$. de yerba cosechada. Por ende, la diferencia entre el pago efectuado y lo que correspondía que se pagase no es irrisorio. Además, "se observa que el $64 \%$ de los cosecheros perciben salarios quincenales inferiores a los $11.000 \mathrm{~m} \$ \mathrm{n}$ [110 \$ ley]. Los cosecheros que reciben una paga superior a los $15.000 \mathrm{~m} \$ \mathrm{n}$ [150 \$ ley] alcanzan el 13\%; pero de éstos ninguno logra ese ingreso trabajando sólo, sino con ayuda del grupo familiar" 39 .

Es así que, si cada tarefero hubiere cosechado $378 \mathrm{Kg}$. de hoja verde de yerba mate por día, trabajando entre 10, 12 e incluso 14 horas diarias, ${ }^{40}$ en promedio 15 días mensuales por 6 o 9 meses, percibió un ingreso quincenal de $7.272 \mathrm{~m} \$ \mathrm{n}$ [72,72 \$ ley], y uno mensual de $14.545 \mathrm{~m} \$ \mathrm{n}[145,45 \$$ ley]. No obstante, se debe clarificar que en la determinación de ese ingreso interviene el precio fijado para el destajo, la forma del mismo, la calidad del objeto de trabajo (estado de la planta), la energía y destreza laboral de los/as cosechero/as, y, lo más importante, "los acuerdos o entendimientos informales entre 'oferentes' y 'demandantes' que usualmente pagaban por debajo de lo establecido anualmente (Rau, 2006, p. 262) ${ }^{41}$. Los/as obreros/as encontraban la necesidad de trabajar una excesiva cantidad de horas, únicamente para cubrir la comida diaria, ya sea mientras estén de campamento o en su casa, dejando de manifiesto que “... el patrón debe utilizar el tiempo de su mano de obra y ver que no se malgaste: no es el quehacer el que domina sino el valor del tiempo al ser reducido a dinero. El tiempo se convierte en moneda: no pasa sino que se gasta" (Thompson, 1984, p. 247; resaltado nuestro).

El tiempo se gasta, porque si trabajaban menos horas no lograrían cosechar los más de 300 kilos de yerba diarios, por los cuales recibirían el porcentaje de dinero como parte del pago a destajo de la yerba. Para dilucidar, se debe entender que, como ocurre aún en la actualidad, el salario de la unidad doméstica que recibía el tarefero era medido por la cantidad de kilos y la calidad de yerba que cosechaba. ${ }^{42}$ Es decir, que es una "forma trasmutada del salario por tiempo" (Marx, 2009, p. 671) donde, en vez de medirse (el trabajo) por tiempo, se deduce por la cantidad de kilos en que se condensa el trabajo, durante determinadas horas, y se le otorga el valor de esa producción. Con esto, es aún más engañosa la impresión, para los/as trabajadores/as, de que el salario es el pago del producto y no de su fuerza de trabajo, cuando en realidad el trabajo a destajo no altera la naturaleza del salario como forma transformada del valor y del precio de su fuerza de trabajo. Por ende, "el salario a destajo no expresa directamente, en realidad, ninguna

${ }^{39}$ GTRS, 1972, p. 9.

${ }^{40}$ De igual manera, trabajar más de 8 hs. diarias no entraba en contradicción con las reglamentaciones vigentes porque las resoluciones de las paritarias del 30 de septiembre de 1971, nombradas con anterioridad, establecieron la jornada laboral "de sol a sol" con pausas para el almuerzo y la merienda, es decir mucho más de 8 horas.

${ }^{41}$ El estudio deja claro -sin hacerlo explicito- que las costumbres, los valores, las normas y entendimientos informales, en algunos casos las redes de confianza, operan como "elementos reguladores del funcionamiento real de las relaciones entre oferentes y demandantes de fuerza de trabajo" (Rau, 2006, p. 280).

${ }^{42}$ El proceso de recolección requiere ser hábil con la tijera o las manos para mantener la calidad, debido a que las hojas no deben quebrarse ni aplastarse durante la cosecha, para no dar inicio prematuramente a la oxidación. Además, se controla si la yerba cosechada tiene más o menos palos. Todo en carácter de mantener la calidad de la mercancía. 
Haugg. La cosecha de yerba mate (tarefa): particularidades de un mercado de trabajo y su circularidad laboral.

proporción. El valor de cada pieza no se mide por el tiempo de trabajo materializado en ella, sino al revés: el trabajo invertido por el obrero se mide por el número, de las piezas que produce" (Marx, 2009, p. 673). En este caso, por la cantidad de kilos de yerba cosechada durante un tiempo determinado.

En vista de ello, y como se mencionó anteriormente, la calidad del trabajo es más que importante a la hora de fijar los "precios" al destajo. El mismo Marx (2009, p. 673) señalaba "la calidad del trabajo está controlada por la obra misma, que debe poseer la calidad media para que se pague íntegramente el precio de cada pieza". Si las hojas de yerba no tienen la calidad solicitada, si la planta se lastimó mientras se cosechaba o no se realizó la poda — solicitada por el productor, el secadero o el contratistael precio de la yerba que percibe el tarefero, como paga, disminuye. Por lo tanto, el asalariado agrícola cobra menos de lo fijado con anterioridad al trabajo. Por ello, los/ as tareferos/as calculaban cuánto recibirían por kilo de yerba linda y por kilo de yerba fea, el tiempo, la tarea, la habilidad y la calidad se complementan en un solo proceso controlado para lograr los kilos estimados por los cosecheros y la paga acordada, como lo expresa un tarefero: "el verdadero tarefero sabe cosechar realmente, ya sabe cuántos kilos va a hacer por día, tiene mano, yo toda mi vida fui tarefero y se tratarle a la planta con cuidado y rápido" ${ }^{\prime 4}$.

Relacionado con este punto clave, se encuentra la forma de pago, que de alguna manera ya fue mencionado, es decir la forma material en que el patrón retribuía el trabajo de sus asalariados, que no siempre adquiría la forma dineraria: "es una práctica muy difundida en las zonas rurales que aquellos empleadores que tienen una cierta cantidad de asalariados, ya sea en forma permanente o transitoria, tengan un almacén para la venta de provisiones a su personal. Los patrones compran semanalmente mercaderías en el pueblo y luego la trasladan con su vehículo hasta la explotación" ${ }^{\prime 4}$. Los empleadores justificaban el funcionamiento de "su" almacén, aduciendo que la mano de obra contratada no contaba con ningún ingreso al inicio de la zafra yerbatera y que ellos se veían "obligados" a "adelantarles" en mercadería parte de la paga ${ }^{45}$. A través del análisis de la encuesta, se pudo determinar que sólo el $52 \%$ de los cosecheros recibían su pago en dinero, mientras que el $31 \%$ de los tareferos recibía su pago en dinero y en provistas, en tanto que el $11 \%$ en dinero y vales y restante el $6 \%$ no recibía dinero, recibiendo vales exclusivamente (5\%) y provistas exclusivamente (1\%). ${ }^{46}$ Entretanto, de todos los anteriores, sólo el $26 \%{ }^{47}$ pagaba sus alimentos en dinero al contado, y el $74 \%$ restante lo hacía mediante distintas formas de pago: descuento directo; dinero pero para pagar la libreta; vales, dinero y vales y otras combinaciones ${ }^{48}$.

\footnotetext{
${ }^{43}$ Tarefero, Oberá, invierno, 2013.

${ }^{44}$ GTSR, 1972, p. 13.

${ }^{45}$ GTSR, 1972.

${ }^{46} \mathrm{La}$ forma dineraria de pago predominaba en secaderos grandes; la de provistas y vales en secaderos pequeños; la de dinero y provistas entre los contratistas y la de dinero y vales en las cooperativas (GTSR, 1972).

${ }^{47}$ De ese $26 \%$ únicamente el $40 \%$ podía elegir comprar en un almacén del pueblo o de la colonia, con lo cual se evitaban pagar un sobreprecio por la mercadería.

${ }^{48}$ GTSR, 1972.
} 
En efecto, el resultado de las anteriores formas de pago arroja una doble dependencia de los/as tareferos/as, como asalariados y como consumidores. Éste último, lleva consigo el sobreprecio que pagaban los/as obreros/as rurales para adquirir sus alimentos en el almacén del empleador. ${ }^{49} \mathrm{El}$ reciente relato de una mujer tarefera, ilustra muy bien sobre esta práctica, a la vez que denota su persistencia hoy en día:

"Muchas veces le sacábamos a nuestros hijos de la escuela y
ahi cuando vamos de campamento... vamos y hablamos porque
hay diferentes capataz de cuadrilla que reúne a la gente para
ir a tarefeary de allí hablamos con un capataz y se ponemos de
acuerdo, vienen los camión grande los que cargan los raidos
de yerba y nos cargan así como vacas con colchón y cosas,
todo arriba, y nos lleva directamente a una cantina. [almacén
del contratista] donde alli nos ahorcan con el precio, alli se
mercamos con nuestra familia y tenemos que llevar..." ${ }_{50}$.

\section{Condiciones de vida: agentes y propensiones socialmente instituidas}

Las condiciones de vida vendrían a describir la realidad de las condiciones socioeconómicas de los/as cosecheros/as de yerba mate, reflejando el modo de inserción de éstos en el mercado de trabajo yerbatero: "el caso del tarefero es uno de los tantos ejemplos de malas condiciones de vida (...) Se podrían detallar su existencia paupérrima, los elevados índices de analfabetismo, la gran mortalidad infantil, las pésimas condiciones salariales, las insuficientes calorías alimentarias, las inadecuadas condiciones habitacionales, etc." ${ }^{2}$. Empero, la descripción detallada de las "malas condiciones de vida" de los/as tareferos/as no nos serviría de mucho, si no analizamos esta realidad como un "círculo vicioso" del que los/as cosecheros/as se veían impedidos de salir, para volver temporada tras temporada. De ello deriva la importancia de conocer, por lo menos en parte, la relación existente entre las paupérrimas condiciones de vida y la ubicación del cosechero en la estructura ocupacional.

En el año analizado, 1971, los tareferos se encontraron ocupados y desocupados, o ambas cosas a la vez. Por ejemplo, para los 561 tareferos encuestados -al parecer todos masculinos- corresponde el número de 1.595 ocupaciones $^{52}$, sin contar las ocupaciones del grupo familiar que también cosechaba, pero no fueron tenidos en cuenta o no estaban al alcance de la encuesta. En el estudio en cuestión, los investigadores pudieron precisar para 1971 diferentes tipos de ocupación y desocupación que presenciaron los

\footnotetext{
49 "La ley autoriza al patrón una sobremarcación del 5\% con la finalidad de cubrir los gastos del flete". Sin embargo, el $47 \%$ de los cosecheros encuestados manifestaron que pagaban un sobreprecio que iba del 11 al $30 \%$, el $23 \%$ dijeron pagar un sobrecargo del 6 al 10\%, e incluso un $4 \%$ declaró pagar entre 40 y $55 \%$ se sobreprecio (GTSR, 1972, p. 16).

${ }^{50}$ Tarefera, Posadas, otoño, 2015.

${ }^{51}$ GTSR, 1972, p. 22.

${ }^{52}$ GTSR, 1972.
} 
Haugg. La cosecha de yerba mate (tarefa): particularidades de un mercado de trabajo y su circularidad laboral.

cosecheros ese año. ${ }^{53}$ Por un lado, predominaba durante la zafra yerbatera la "ocupación precaria" ${ }^{54}$. Esto refiere a la precariedad, devenida de la combinación de: inestabilidad (del empleo y de los ingresos), no registración, condiciones de vida deterioradas (viviendas precarias, hacinamiento, malas condiciones sanitarias en los yerbales, bajo nivel de consumo familiar de alimentos, paga en alimentos, analfabetismos, entre otros) y de trabajo (trabajar de "sol a sol", forzar el cuerpo a tareas pesadas, traslado a los yerbales, entre otros). Por ello, es importante destacar que, "una de las conclusiones más importantes del estudio es que la situación de 'ocupación precaria' afecta a la totalidad de los trabajadores transitorios" ${ }^{\prime 5}$.

Por otro lado, el mercado yerbatero absorbía un elevado número de mano de obra en determinados períodos del año, pero fuera de él prevalecía el fenómeno de la "desocupación estacional", la que, en ocasiones, se transformaba en "desocupación abierta" "56. Esta última, no era la más relevante en esos años, -hoy sí- porque los/as cosecheros/as una vez terminada la cosecha de yerba mate, habían tenido más de una ocupación. A partir de esto, el estudio sostiene que "el cosechero de Misiones tiene limitadas posibilidades ocupacionales, las cuales provienen casi exclusivamente del sector rural, y dentro de éste de tareas de tipo estacional o intermitente" ${ }^{57}$. Lo cual sugiere que los/as tareferos/as tienen una inserción no estable en los mercados de trabajo, no sólo en el yerbatero.

En definitiva, se puede establecer escuetamente que los ingresos de los/as cosecheros/as de yerba mate eran insuficientes para suplir sus necesidades básicas, que las condiciones de trabajo eran desfavorables, predominando la precariedad laboral y formas de pago en vales y provistas. Además, estaban en constante endeudamiento, debía trabajar toda la unidad doméstica - pero sólo el contratado directo recibía la paga-, tenían un nivel de escolaridad muy bajo -predominando el analfabetismo-. Por otro lado, presentaban una elevada movilidad ocupacional y circularidad laboral interdepartamental. Es decir, que los/as tareferos/as reproducían sus vidas sometidos a condiciones circulares, inestables e insalubres de trabajo, condiciones de pobreza extremas, formas particulares de organización doméstica y relaciones históricas de poder, hechas cuerpo a lo largo de la existencia social del agente social cosechero de yerba mate. Creemos que semejante funcionamiento del mercado de trabajo, en contraposición a la economía neoclásica, no se rige de acuerdo al supuesto del "individualismo metodológico", donde cada agente es igual y debe recibir una retribución acorde al factor que representa, ni mucho menos se trata de agentes omniscientes inclinados a la maximización. Si no, que los comportamientos económicos se originan en la "interacción social recurrente, adquieren solidez allí como instituciones, al mismo tiempo que son sustentadas por la tendencia perdurable de los habitus, de las disposiciones prácticas adquiridas históricamente por los sujetos" (Rau, 2006, p. 280).

\footnotetext{
${ }^{53}$ El sociólogo Víctor Rau los definiría como "semiocupados" (Rau, 2005, p. 286).

${ }^{54}$ GTSR, 1972, p. 40.

${ }^{55}$ GTSR, 1972, p. 41.

${ }^{56}$ GTSR, 1972, pp. 39-41.

${ }^{57}$ GTSR, 1972, p. 50.
} 
Es en relación con esto que, lejos de cualquier elección, casi la totalidad de los/ as tareferos/as, entrevistados/as en la actualidad, afirmó formar parte de familias que llevan varias generaciones siendo tareferos/as. Enuncian que sus padres y abuelos fueron tareferos, que desde niños tuvieron que ir al yerbal y aprendieron a cosechar observando cómo lo hacían sus padres o jugando, debido a que la familia entera se trasladaba al lugar de trabajo bajo modalidad de acampe ${ }^{58}$. Esto se hace notar reproduciendo sólo algunos fragmentos de entrevistas: "El hijo de tarefero siempre fue tarefero"59; "yo fui tarefero porque mis padres fueron tareferos" 60 ; "mi mamá era tarefera y teníamos que dejar la escuela para ir a tarefear, por eso soy una mujer tarefera" ${ }^{\prime \prime 1}$. Si bien sólo se citan pocos y pequeños fragmentos de interesantes entrevistas, ellas ponen de manifiesto la compleja y circular dinámica en la que los agentes sociales están inmersos en el mercado de trabajo cosechero/yerbatero y que, el mismo, está atravesado por relaciones sociales que se replican de antaño. Los/as cosecheros/as de yerba mate no viven en compartimentos que separan lo formal de lo informal, lo social de lo económico o lo familiar de lo productivo, en tanto se considera a la tarefa como trabajo familiar.

De igual manera, no logramos encontrar en el "Estudio de la mano de obra transitoria de la Provincia de Misiones", ni en las entrevistas, acciones producto de una "intención económica", mucho menos de cálculos o persecuciones conscientes de fines, sino disposiciones interiorizadas, propensiones e inclinaciones socialmente instituidas que operan dentro del mercado de trabajo cosechero/yerbatero. Es así que, la afirmación de los/as cosecheros/as acerca de su dificultad para salir de la tarefa-que se volvió un círculo vicioso que se repite generación tras generación-, nos permite argüir que la tarefa es una práctica incorporada y a la que siempre se vuelve, aunque no se quiera hacerlo, no por la tarefa en sí, sino por las características en las que se desarrolla la misma. Por lo que, el trabajo como cosecheros/as en vez de representar una realización espontánea y alegre, lo que hace es frenar cualquier tipo de satisfacción intrínseca.

Entonces, efectivamente, en este mercado laboral, estamos ante la presencia de un "acuerdo libre" entre los agentes que participan del mismo. Pero ese "acuerdo libre" refiere únicamente a que carece de sujeción personal en términos legales, puesto que los/ as tareferos/as estaban -y están- atravesados por condiciones sociales particulares que no podían manejar a su arbitrio. Dejando en claro, que “...el mundo social es historia acumulada" (Bourdieu, 2015, p. 131), y la acumulación de esta historia es incorporada en los cuerpos vivientes de los agentes (tareferos $/$ as) $),{ }^{62}$ y objetivada en las instituciones sociales (la familia, el estado-sistema, el mercado de trabajo cosechero/yerbatero, etc.). En fin, bajo lo socialmente dado, vive lo históricamente constituido, en relación a las

\footnotetext{
${ }^{58}$ Reafirmando que no hay una pedagogía que enseñe a ser tarefero/a, sino que es una práctica incorporada a través de la observación, mímesis o repetición (Roa, 2013).

59 Tarefera, Oberá, verano, 2014.

${ }^{60}$ Tarefero, Posadas, otoño, 2015.

${ }^{61}$ Tarefera, Oberá, invierno, 2015.

62 "El habitus es la presencia actuante de todo el pasado del cual es el producto". Disposiciones a actuar, a pensar a percibir más de una manera que de otra, relacionadas a "esto es para mí" y "esto no es para mí", a "lo pensable" y "lo no pensable", obrando en consecuencia (Bourdieu, 2015, p. 92).
} 
Haugg. La cosecha de yerba mate (tarefa): particularidades de un mercado de trabajo y su circularidad laboral.

especificidades que regulan el mercado cosechero/yerbatero, la circularidad de mano de obra y las prácticas entre empleadores y empleados.

\section{Los números hechos carne: La tarefa que circula}

Para hacer más elocuente el tema y expresar mejor a qué nos referimos con la circulación de la actividad -laboral y generacional-, la razón por la cual circula la actividad y qué opciones tienen las familias de no reproducir la actividad, hemos seleccionado, la trayectoria de Norma. Ella es una mujer tarefera de 53 años, que será reconstruida en términos individuales pero siempre en el marco relacional de su trayectoria de clase y de su género. Nació en 1967 en la localidad de Panambí, Misiones. ${ }^{63}$ Allí, su unidad doméstica estaba conformada por su padre, su madre y dos hermanas, todos/as tareferos/as, hijos/as de tareferos/as -abuelos/as y bisabuelos/as-. Nadie en la familia había asistido a la escuela, por lo que ninguno de los cinco integrantes sabía leer y escribir. En su niñez y adolescencia, hacía trabajos de tarefa, circulando por distintos yerbales lejanos a su domicilio, pero no se identificaba como tarefera, ya que el padre era el que recibía la remuneración por el trabajo de toda la unidad doméstica. En épocas de interzafra, trabajaban en la chacra familiar donde plantaban mandioca, batata, zapallo, lechuga, acelga, cebollita, perejil, orégano. Además, contaban con algunas aves de corral (gallinas). Todos estos recursos de los que disponían paliaban y satisfacían sus necesidades alimenticias, complementadas con algunos granos y carnes, a los que accedían mediante trabajos temporales del padre en alguna actividad agrícola.

A los 13 años, Norma comenzó a cosechar bastante raídos por día, lo que demostraba la corporización del ser tarefero/a. A los 15 años, y durante 6 meses, trabajó en un secadero barbacuá, donde desempeñó tareas expuesta a más de $100^{\circ}$, como foguista (haciendo fuego en el horno), planchadera (arrimando la yerba al fuego para zapecarla) y retiradora (retirando la yerba del fuego y colocándola en un canasto). Además, fue embolsadora de yerba -cosía bolsas para formar los raídos, y las apilaba-. Luego, por varios años, en la fase contraestacional de cosecha, trabajaba 3 meses en secaderos a cinta como embolsadora. Todas sus labores estaban relacionadas con la yerba mate, siendo su principal ocupación la cosecha de la misma, en carácter de "ayuda familiar".

Ya finalizando la década de 1980, el padre y una hermana fallecen. El primero producto del trabajo penoso en el yerbal y, la segunda -a los 19 años- a causa de una descarga eléctrica en la vivienda por un tendido eléctrico irregular. En ese contexto, no consiguiendo trabajo en la tarefa, ni en otras actividades agrícolas porque "en esos años empezaron a contratar más en las ciudades", las tres mujeres restantes deciden abandonar las tierras. En ellas trabajaron por años, en carácter de ocupantes, para trasladarse a los márgenes de la ciudad de Oberá, en un barrio nombrado Cien Hectáreas, que pronto -en los 90'- se convirtió en un barrio tarefero por excelencia. En este nuevo domicilio, les fue imposible contar con una chacra familiar como lo hacían en Panambí, ya que, si bien el predio era grande, lindaba con un pequeño arroyo sin sanear, lo que provoca que todo

\footnotetext{
${ }^{63}$ Es una pequeña localidad rural, contaba con 469 habitantes en la década de 1990, según el Censo
} Nacional de Población y Viviendas de 1991 (IPEC, 1993). 
el terreno se inunde cada vez que llovía. Al poco tiempo, Norma, sin abandonar jamás su trabajo en la tarefa, conformó una nueva unidad doméstica con marido -tarefero- e hijos/as, por lo que la madre y la hermana siguieron habitando la casa. No obstante, ella y su marido construyeron, en el mismo terreno, un monoambiente de machimbre y, a unos cuantos metros, una cocina con bolsas de polietileno. De esa relación, nacieron 12 hijos/ as, de los cuales tres nacieron en el yerbal, dos en la casa y siete en el hospital de Oberá.

Por su parte, la madre de Norma, "empezó a trabajar como tarefera" cuando falleció su marido, "antes sólo ayudaba", y Norma hizo lo mismo. Cuando su marido "abandonó a sus hijos", ella comenzó a trabajar por una remuneración propia, no individual, ya que los/as hijos/as ocupaban el lugar de "ayuda" que ella ya había abandonado. Norma sostiene que, si bien los/as niños/as abandonaron la escuela en los primeros grados para poder trabajar, "ellos saben hacer todo, fueron criados en el trabajo". Ese ser "criados en el trabajo" conllevó a que los mismos circulasen para cosechar, junto a sus progenitores -luego sólo su madre- por distintos poblados de la provincia, como San Pedro, San Vicente, Colonia Paraíso, Los Naranjales, El Soberbio, Colonia La Flores, Los Helechos, Campo Grande, Puerto Esperanza, entre otros. Los 12 hijos/as de Norma trabajaron como tareferos/as, al día de hoy solo dos de ellos no lo hacen. Uno es vendedor ambulante de chipas de almidón y otra se desempeña como empleada doméstica, pero no descartan la posibilidad de verse obligados a volver a los yerbales. Asimismo, los/as nietos/as ya han ido a los yerbales en compañía de sus padres y/o madres, por no contar con salas de contención y cuidados para los/as menores.

A la vez, es importante mencionar que por años Norma formó una unidad doméstica monoparental con jefatura femenina, siendo el salario percibido por su labor como tarefera el principal ingreso familiar ${ }^{64}$. Asimismo, durante los meses de interzafra aparecían una combinación de diversas estrategias desplegadas por todos los miembros, y redes sociales puestas en funcionamiento, que auspiciaban como "redes de ayuda" para la producción y reproducción de la unidad doméstica. Una de esas estrategias consiste en participar de movilizaciones y protestas tareferas, en la ciudad de Oberá o en Posadas, frente a dependencias como la Municipalidad, el Ministerio de Trabajo, el Ministerio de Desarrollo Social o la Casa de Gobernación provincial en busca de "puestos de trabajo de barrido o limpieza de calles y bolsas de mercadería", casi nunca otorgados. Otro objetivo de la movilización es percibir "ayuda" de la población civil, en carácter de alimentos, ropas y calzados ${ }^{65}$. Además, sin ir más lejos, en el mismo barrio -o en el barrio vecino San Miguel- entablan con vecinos/as redes recíprocas de ayuda con alimentos. Casi la totalidad de los habitantes de los dos barrios son tareferos/

${ }^{64}$ En dos ocasiones tuvo que trabajar convaleciente, tras sufrir caídas de los camiones con los que los transportaban a los yerbales.

${ }^{65}$ Ningún integrante de la unidad doméstica era -al momento de la entrevista- beneficiario de programas sociales como la Asignación Universal por Hijo/a (AUH) ni las pensiones a la vejez, Jubilación No Contributiva. Es importante mencionar que, cuando establecimos una relación de confianza, Norma nos comenta que quería que su madre se jubile para mejorar su calidad de vida, ya que trabajó la mayor parte de su vida, pero nunca tuvo la oportunidad de realizar los aportes previsionales. Hoy en día, pese a los obstáculos, su madre es "jubilada". Además, sus hijas cobran la AUH. 
Haugg. La cosecha de yerba mate (tarefa): particularidades de un mercado de trabajo y su circularidad laboral.

as, o bien se dedican mayormente a la tarefa. El/la vecino/a que tiene, por ejemplo, dos paquetes de azúcar y dos botellas de aceite, le brinda una al vecino/a que "más lo necesite", luego en momentos de "apriete" el/la que donó es el/la receptor/a. ${ }^{66}$

No obstante, el principal ingreso en épocas interzafra es la reorganización del trabajo de los miembros de la unidad doméstica como pluriactivadad, "volteada de montes, cortes de pasto, limpieza de terrenos, lavado de ropa y limpieza de casas, el trabajo que se podía hacer se hacía". Todas estas actividades son temporarias y sumamente precarias, por lo que los miembros deben volver a la tarefa nuevamente al inicio de la zafra, y agradecer por ello: "gracias a Dios siempre tenemos la tarefa, sino no sé de qué vivimos". Así, esto aparecía como lo único "posible" y "pensable", ya que "para eso somos nosotros, para ser tareferos". Otra vez en la zafra yerbatera, la organización de la unidad doméstica de Norma sigue el ritmo recurrente, y si se trabaja en familia, mejor: el "raído familiar es el que más rinde".

El reconstruir la -síntesis de- trayectoria de Norma como hija-ayudante, esposa-madre-ayudante y madre soltera-mujer tarefera, nos permite "encarnar" los números que arrojó el estudio del GTSR para dar cuenta de relaciones incorporadas hechas cuerpo a lo largo de una trayectoria social. A raíz de ello, se señaló, en parte, como factor explicativo a los ya mencionados habitus incorporados, propuestos por Pierre Bourdieu, como responsables de la circulación de la tarefa por generaciones, actividad que es resistida, pero siempre retomada año tras año.

\section{Consideraciones finales}

Desde la realización de la encuesta en 1971 —divulgada en 1972- pasaron poco más de tres décadas hasta que se realizaron nuevas investigaciones relacionadas a la mano de obra rural cosechera de yerba mate de la mano del sociólogo Víctor Rau (2002). Esto deja en evidencia cambios significativos respecto a diversas características. Las principales son:

Primero, en lo que concierne a la residencia rural de los/as tareferos/as. Para la década de 1970 predominaba la residencia rural de los mismos. En cambio para los años 2000, en algunas zonas abordadas por el sociólogo, predominaba la residencia periurbana de los/as tareferos/as. No obstante, existen complejidades zonales y locales que exhiben que, a pesar del importante grado de urbanización de la mano de obra, la residencia rural de los/as trabajadores/as continúa predominando sobre el conjunto (Rau, 2016). Segundo, en la época analizada por el GTSR, se encontró una población rural predominantemente ocupada a lo largo de todo el ciclo anual, siendo la tarefa la principal

\footnotetext{
${ }^{66}$ En una oportunidad en la que nos encontrábamos haciendo trabajo de campo, nos despedíamos de Norma para ir a la casa de otra tarefera que se encontraba a tres cuadras, entonces Norma que vivía en una pobreza absoluta donde todos sus derechos eran vulnerados y su dieta alimenticia era insuficiente, carga alimentos en una bolsa de nylon y los lleva consigo mientras nos acompaña. Una cuadra antes de llegar a la casa de la vecina, paramos frente a una dirección desconocida donde se acerca un hombre y Norma le hace entrega de la bolsa, este le agradece y nos comenta su situación y el motivo por el cual recibió esa "ayuda". Sucedía que el vecino tenía a una de sus hijas enferma, y ante la falta de recursos en el hospital público, debía hacerle estudios en uno privado, por lo que todos sus recursos eran destinados a eso.
} 
ocupación y otras tantas luego de su finalización -especialmente las relacionadas a la agricultura, como se explicitó con anterioridad-. Ya para los años 2000,-iniciándose en los noventa- los nuevos estudios se encontraron con un aumento de la oferta de mano de obra tarefera, con largos períodos de desempleo durante la fase contraestacional de cosecha. Tercero, mientras que el GTSR halló un pequeño número de agentes de países limítrofes que se encontraban realizando tareas de cosecha, ya para los años $2000 \mathrm{su}$ presencia era nula, a causa de la sobreoferta de mano de obra local.

Todo lo expuesto demuestra los cambios significativos que atravesó el/la agente encargado/a de cosechar yerba mate. Pasó de ser un/a trabajador/a rural, con residencia rural, ocupado/a durante todo el ciclo anual, a ser un/a trabajador/a rural con residencia urbana o periurbana -para algunos casos-, semi-ocupado/a que alterna su trabajo en la tarefa con largos períodos de inactividad, a no ser con trabajos esporádicos y de muy bajos ingresos. Así, a pesar de ver trastocada su "organización", su "modo de vida", su "mundo posible", los/as tareferos/as no desaparecieron, más bien estructuraron un conjunto de prácticas que les permitió reproducirse socialmente en tales condiciones.

Escapó a los alcances del presente trabajo realizar un análisis comparativo entre los diferentes períodos históricos, ya que actualmente son bastantes los estudios que abordan la problemática en el empleo rural cosechero de yerba mate. Más bien, se orientó en brindar una caracterización generalizada de la situación de los/as tareferos/as y el problema de su "circularidad" en el período en el que el GTSR realizó su estudio, el cual es poco consultado a pesar de ser sumamente relevante para el estudio de la mano de obra tarefera. Por ello, la incorporación de la trayectoria social dio cuenta de las coerciones estructurales que recaen sobre los/as tareferos/as, y a su vez las posibilidades de respuestas de los/as agentes ante dichas coerciones. Por lo que, si bien en los apartados anteriores describimos y analizamos las particularidades del mercado de trabajo cosechero de yerba mate y su consiguiente circularidad laboral, creemos que no basta con describir las condiciones materiales de vida y trabajo, lo "posible" y lo "no posible" que implican y embeben a los agentes encargados de cosechar yerba mate día a día. Se impone, también, rescatar a quienes viven en ese mundo y el modo en el que lo perciben, lo sienten, lo analizan, lo piensan y actúan en él.

\section{Referencias bibliográficas}

Amable, H. (2012). Las figuras del habla misionera. Posadas: EdUNaM.

Bendini, M. \& Steimbreger, N. (2010). “Trabajadores golondrinas y nuevas aéreas frutícolas. Las nuevas temporadas, otros territorios”. En S. Lara Flores (comp.), Migraciones de Trabajo y movilidad territorial, (pp. 281-306). Ciudad de México: Miguel Ángel Porrúa.

Bourdieu, P. (2015). El sentido práctico. Buenos Aires: Siglo XXI.

Bourdieu P. (2000). La dominación masculina. Barcelona: Anagrama.

Carton de Grammont, H. (2009). "La desagrarización del campo mexicano". Convergencia. Revista de Ciencias Sociales, 16(50), 13-55. 
Haugg. La cosecha de yerba mate (tarefa): particularidades de un mercado de trabajo y su circularidad laboral.

Chapman, M. \& Prothero, M. (1984). "Themes on Circulation in the Third World". International Migration Review, 17(4), 597-632. ISSN: 1747-7379. Recuperado de: https://doi.org/10.1177/019791838301700402

Chapman, M. \& Prothero, M. (1985). Circulation in population movement: Substance and concepts from the Melanesian case. London: Routledge \& Kegan Paul Plc.

Gmelch, J. (1980). "Return Migration". Annual Review of Anthropology, 9, 135159. ISSN: 1545-4290. Recuperado de: https://doi.org/10.1146/annurev. an.09.100180.001031

Godelier, M. (1967). "Objeto y método de la Antropología Económica". Ideas y Valores, 27-29, 3-31. ISSN: 0120-0062. Recuperado de: https://revistas.unal.edu.co/index. $\mathrm{php} / \mathrm{idval} / \mathrm{article} / \mathrm{view} / 28921 / 29207$

Gortari, J. (2017). “Los mensúes del siglo XXI”. En Gortari, J., Re, D., Roa, M. (coords.), Tareferos. Vida y trabajo en los yerbales, (pp. 91-119). Posadas: EDUNAM.

Gortari, J., Re, D., Roa. M. L. (coords) (2017). Tareferos. Vida y trabajo en los yerbales. Posadas, Argentina: EDUNAM.

Haugg, D. (2018). “'Ahora trabajo, antes sólo ayudaba': algunas aproximaciones históricas al trabajo femenino en los yerbales. Oberá, Misiones, Argentina”. En Jaume, F. (comp), Luchas por la hegemonía. Historia y etnografía en la Provincia de Misiones, Argentina, (pp. 331-370). Posadas: EDUNAM.

INYM (2019). "En mayo, el consumo de yerba mate mantuvo su tendencia positiva". Recuperado de: https://www.inym.org.ar/en-mayo-el-consumo-de-yerba-matemantuvo-su-tendencia-positiva/

Lara Flores, S. (2010). "Los 'encadenamientos migratorios' en regiones de agricultura intensiva de exportación en México". En Lara Flores, S. (comp.), Migraciones de Trabajo y movilidad territorial, (pp. 251-279). Ciudad de México: Miguel Ángel Porrúa.

Lara Flores, S. (2001). "Análisis del mercado de trabajo rural en México en un contexto de flexibilización”. En N. Giarracca (comp.), ¿Una Nueva Ruralidad en América Latina?, (pp. 363-382). Buenos Aires: CLACSO.

Marx, K. (2009). El Capital. Critica de la Economía Política. Ciudad de México: Siglo XXI. Meillassoux, C. (1977). Mujeres, graneros y capitales. Ciudad de México: Siglo XXI

Polanyi, K. (1976). "La economía como proceso institucionalizado". En M. Godelier (comp.), Antropología y economía, (pp. 155-178). Barcelona: Anagrama

Polanyi, K. (2007). La gran transformación. Los orígenes políticos y económicos de nuestro tiempo. Buenos Aires: Fondo de Cultura Económica.

Quaranta, G. y Blanco, M. (2012). "Formas actuales de circulación y conformación de patrones migratorios de hogares rurales en la provincia de Santiago del Estero, Argentina”. RURIS, 6(1), 127-158.

Rau, V. (2002). "Condiciones para la venta de capacidad laboral cosechera en el mercado de trabajo de la yerba mate". Estudios del Trabajo, 24, 103-115. ISSN: 0327-5744.

Rau, V. (2005). Los cosecheros de yerba mate. Mercado de trabajo agrario y lucha social en Misiones. Tesis doctoral. Universidad de Buenos Aires. Repositorio UBA.

Rau, V. (2006): "La sociología de los mercados laborales en los estudios sobre el empleo agrícola”. Revista Gaceta Laboral, 12, 357-367. ISSN: 1315-8597 
Rau, V. (2016): "El trabajo asalariado agropecuario en la región yerbatera argentina. Imágenes de situación en datos cuantitativos". Mundo Agrario, 17(36). ISSN: 1515-5994. Recuperado de: https:/www.mundoagrario.unlp.edu.ar/article/view/ MAe030/7766

Re, D. (2015). "La ayuda infantil en la tarefa de yerba mate. Cultura, mercado y legislación". Revista Conflicto social, 8(14), 221-242.

Roa, Ma. L. (2013). “Tarefa que me hiciste sufrir... La emocionalidad en la constitución del self de los jóvenes de familias tareferas". Trabajo y Sociedad, 20, 323-343. ISSN: 1514- 6871. Recuperado de: https://www.unse.edu.ar/trabajoysociedad/20\%20 ROA\%20emocionalidad\%20jovenes\%20tareferos.pdf

Tarrius, A. (2000). "Leer, describir, interpretar. Las circulaciones migratorias: conveniencia de la noción de 'territorio circulatorio'. Los nuevos hábitos de la identidad". Relaciones. Estudios de historia y sociedad, 83, 39-66. ISSN: 0185-3929

Thompson, E. P. (1984). Tradición, revuelta y consciencia de clase. Barcelona, España: Editorial Crítica.

Trpin, V. \& Rodríguez, M. (2015). "Mercados de trabajo y movilidad de trabajadores de origen chileno en el norte de la Patagonia". Polis. Revista Latinoamericana, 41, 1-17. ISSN: 0718-6568. Recuperado de: https://journals.openedition.org/polis/11132

\section{Fuentes}

Grupo de trabajo en Sociología Rural -GTSR- (1972). Estudio de la mano de obra transitoria en la Provincia de Misiones. Buenos Aires, Argentina: Dirección Nacional de Economía y Sociología.

IPEC (1993). Censo Nacional de Población y Viviendas 1991. Total País. Resultados definitivos. Serie C.

\section{Entrevistas}

Entrevistas a tareferos y tareferas,

Obéra, invierno 2013, verano 2014, invierno 2015, invierno 2018.

Posadas, otoño 2015, verano 2015, otoño 2017. 